\title{
Adolescents' awareness and use of menu labels in eating establishments: results from a focus group study
}

\author{
Alexandra E Evans ${ }^{1, *}$, Samantha R Weiss ${ }^{1}$, Kerry J Meath ${ }^{1}$, Sherman Chow ${ }^{1}$, \\ Elizabeth A Vandewater ${ }^{1}$ and Roberta B Ness ${ }^{2}$ \\ ${ }^{1}$ Michael \& Susan Dell Center for Healthy Living, University of Texas School of Public Health - Austin Regional \\ Campus, 1616 Guadalupe, Suite 6.300, Austin, TX 78701, USA: ${ }^{2}$ University of Texas School of Public Health - \\ Houston, Houston, TX, USA
}

Submitted 19 September 2014: Final revision received 30 January 2015: Accepted 6 March 2015: First published online 21 April 2015

\begin{abstract}
Objective: Menu labelling has been identified as a potential strategy to help individuals make healthier choices when eating out. Although adolescents eat out often, little research involving menu labelling has been conducted with this population. The objectives of the present study were to: (i) gather qualitative information from adolescents regarding use of menu labels when eating out; (ii) gather adolescents' suggestions for optimal ways to design menu labels; and (iii) examine differences between adolescents living in communities of different socio-economic status.

Design: Qualitative. Five focus groups of five to ten participants.

Setting: Austin, TX, USA, 2012.

Subjects: Forty-one adolescents living in diverse communities recruited using a snowballing technique at public and private recreation centres (twenty-four females; twenty-two African American).

Results: Participants reported that menu labelling, in general, does not influence food selections when eating out. Among participants living in low-income communities, food purchases were based on price, taste and familiarity. Among participants living in high-income areas, food purchases were based on quality and ability to satiate (among boys). According to participants, effective ways to present menu labels are by matching calorie levels with physical activity equivalents or through simple graphics.

Conclusions: For adolescents, providing menu labels in their current format may not be an effective strategy to increase healthy food selection. Given that the current menu label format has been set by federal policy in the USA cannot be easily changed, research to determine how this format can be best presented or enhanced so that it can have an impact on all US sub-populations is warranted.
\end{abstract}

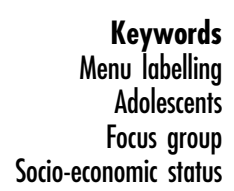

Currently, Americans spend approximately $50 \%$ of their food budget on foods eaten outside the home ${ }^{(1)}$, representing a substantial increase from $18 \%$ reported 30 years ago ${ }^{(2)}$. Eating out is related to higher intakes of energy and fat $^{(3-9)}$ and to higher rates of overweight and obesity ${ }^{(10)}$. Evidence suggests that Americans consistently underestimate the energy content (number of calories) of restaurant foods ${ }^{(11-16)}$. Menu labelling, such as posting energy (caloric) content of foods at the point of purchase in restaurants, has been proposed as one strategy to allow consumers to make informed food purchases. In contrast to complicated and expensive media literacy or nutrition education interventions, menu labels have the advantage of being relatively inexpensive, relatively easy to implement and concurrent with food purchases. However, results from studies examining the effectiveness of menu labels on food purchases have been mixed ${ }^{(17-34)}$. Nevertheless, in March 2010, Congress passed the Patient Protection and Affordable Care Act requiring chain restaurants with twenty or more outlets to start listing caloric information on their menu boards after issuance of final rules, anticipated in $2014^{(35)}$.

In terms of menu labelling, adolescents are a group of particular interest. It is estimated that adolescents directly purchase \$US 14 billion in goods annually and influence another \$US 190 billion in family purchases, comprising mostly food ${ }^{(36,37)}$. Moreover, adolescents tend to eat out regularly ${ }^{(38,39)}$, putting them at risk for increased 
consumption of calorically dense foods and weight gain. Although adolescents as a group tend to eat out often, very little research related to menu labels has specifically targeted this group and, to the best of our knowledge, no study has collected qualitative data from adolescents on the topic of menu labels ${ }^{(25,40-42)}$. Therefore, the primary aim of the present study was to gather qualitative information from adolescents regarding their awareness and use of menu labels when eating out, and their suggestions for optimal ways to design menu labels. In addition, because of the noted disparities in availability of healthy foods in lower- $v$. higher-income communities ${ }^{(43-46)}$, the secondary aim of the study was to explore differences in responses from adolescents living in communities of different socio-economic status.

\section{Methods}

The present qualitative study collected and analysed data from forty-one adolescents of high school age through five focus groups conducted in Austin, TX, USA during 2012. The researchers chose the focus group methodology for the study because it can provide more information than self-report surveys and it allows some group interaction among the focus group participants, which is particularly useful when collecting information from adolescents ${ }^{(47)}$. The study was approved by the Institutional Review Board of the University of Texas Health Science Center.

\section{Participants}

In order to achieve a study sample with diverse socioeconomic status, adolescents were recruited at public recreation centres located in lower-income communities and at private recreation clubs located in higher-income communities using recruitment posters. In addition, staff at the recreation clubs announced the study to their eligible youth and verbally invited them to participate. These two settings were specifically chosen because members of the different clubs (i.e. public $v$. private) would allow the recruitment of participants of low and high socioeconomic status. The snowballing technique was used to meet the recruitment goal of at least forty adolescents.

Potential participants were asked to meet at a specific time at a public location (either the public recreation centres or an eating establishment near the private recreation centres where respective participants were recruited). Forty-one participants met the inclusion criteria of age (14-19 years) and ability to communicate in English. Before each focus group session, research staff obtained written parental consent by sending consent forms home with parents. Consent forms were available in English and Spanish. Student assent was obtained from all participants at the beginning of the focus group. Participants were informed that participation was confidential, voluntary, and that they could withdraw at any time. However, if participants would have withdrawn half way through the focus group, their data would still have been included in the analysis. No identifiers (i.e. names of participants) were used during the focus group discussions to increase anonymity. Participants were also informed before the start of the session that sessions were audio-recorded.

\section{Focus group questions}

Based on the socio-ecological framework ${ }^{(48)}$, the focus group questions were developed to elicit data related to individual behaviour (i.e. current use of menu labels) and other intrapersonal factors (i.e. exposure to menu labels), interpersonal variables (i.e. influence of friends and family) and the influence of the larger food environment (location and cost). Additionally, information related to optimal ways to design menu labels for restaurants was elicited.

\section{Data collection}

Three trained moderators (authors S.C., K.J.M. and S.R.W.) conducted all five focus groups using a standardized protocol of focus group questions and probes ${ }^{(49)}$. The focus group protocol was based on previous qualitative studies conducted by the research team ${ }^{(50,51)}$. The specific questions for the present study were field tested with three adolescents before the questions were used in the field. Each focus group ranged from five to ten participants. At the start of each focus group, participants completed a demographic questionnaire, including age, gender, ethnicity/race and usual practices related to using menu labels. Fruit trays and water were provided during each session for snacks. Sessions lasted approximately $50 \mathrm{~min}$ and were audio-recorded. The focus group tapes were transcribed by the three moderators and checked for accuracy by the principal investigator (author A.E.E.). Participants were provided a \$US 20 gift card after completion of the focus group.

\section{Data analysis}

Descriptive analyses were conducted on the survey responses. Qualitative data analysis consisted of creating a coding scheme based on the focus group questions and responses, and a set of decision rules was established to standardize coding procedure ${ }^{(52)}$. Analysis was conducted using the qualitative software QSR NVivo version 8 (2008). Coding involved structured organizing of transcript passages into categories to facilitate data analysis and interpretation. Primary themes were identified through frequency of coding within similar social contexts and across focus groups. Each transcript was coded by at least two coders and differences were discussed until agreement was reached. The two coders (S.C. and S.R.W.) were staff with experience in qualitative methodology and were both focus group moderators as well. 


\section{Results}

\section{Participants}

Forty-one adolescents participated in five focus groups. The majority of the lower-income community participants ( $n$ 26) were female and Black, and $50 \%$ of this group participated in the free or reduced-price National School Lunch Program. Most of the higher-income community participants ( $n$ 15) were non-Hispanic White females and none participated in the National School Lunch Program (Table 1).

The vast majority of lower-income students reported eating at fast-food establishments during the past week (96\%). Forty-six per cent of this group spent more than \$US 10 per week eating out. In contrast, only $40 \%$ of higher-income adolescents reported eating at fast-food restaurants in the past week; $20 \%$ spent more than \$US 10. The majority of participants from both groups reported that menu labels did not influence their food purchasing decisions (Table 2).

\section{Emergent themes from qualitative data}

Four overarching themes emerged from the focus group discussions: (i) knowledge about caloric requirements; (ii) menu labelling awareness and use; (iii) influences on food purchasing behaviours; and (iv) strategies for effective menu labels. Direct quotations supporting these themes are provided in Table 3 .

\section{Knowledge about caloric requirements}

In general, girls living in the higher-income communities were knowledgeable about the appropriate daily intake of calories. These girls also expressed a desire to learn more about calories and nutrition, illustrated by their questions to interviewers during the focus groups. Adolescents living in the low-income communities suggested a range of appropriate daily caloric intake between 20 and 10000 calories (84 and $41840 \mathrm{~kJ}$ ). These participants reported having mixed feelings about learning more nutrition information.

\section{Menu labelling awareness and use}

At the time of the present study, the Patient Protection and Affordable Care Act was not yet in place but several chain restaurants had already implemented menu labelling. Although the majority of participants were knowledgeable about menu labelling, the majority of the participants reported rarely noticing menu labels at eating establishments. They also reported that when they did notice menu labels, they were rarely interested in reading them (Table 3, row B) Additionally, most participants felt they would only become interested in menu labels if they might be personally affected by overweight or weight-related illness (Table 3, row C).

\section{Influences on food purchasing decisions}

Although participants were clear that menu labelling did not affect food purchasing decisions, analyses did reveal five other factors.

Characteristics of the food. Except for higher-income community girls, participants reported caloric content as rarely influential in their food purchasing decisions. Instead, cost and taste were cited as the most important factors influencing food choices. However, girls from the

Table 1 Demographic characteristics of the adolescent participants ( $n$ 41) according to SES, Austin, TX, USA, 2012

\begin{tabular}{|c|c|c|c|c|}
\hline \multirow[b]{2}{*}{ Characteristic } & \multicolumn{2}{|c|}{ Lower SES ( $n$ 26) } & \multicolumn{2}{|c|}{ Higher SES ( $n$ 15) } \\
\hline & $n$ & $\%$ & $n$ & $\%$ \\
\hline \multicolumn{5}{|l|}{ Gender } \\
\hline Male & 9 & 34.6 & 6 & $40 \cdot 0$ \\
\hline Female & 15 & $57 \cdot 7$ & 9 & $60 \cdot 0$ \\
\hline Missing & 2 & $7 \cdot 7$ & 0 & 0.0 \\
\hline \multicolumn{5}{|l|}{ Age (years) } \\
\hline 14 & 6 & 23.1 & 2 & $13 \cdot 3$ \\
\hline 15 & 3 & 11.5 & 7 & $46 \cdot 7$ \\
\hline 16 & 5 & $19 \cdot 2$ & 4 & $26 \cdot 7$ \\
\hline 17 & 7 & $26 \cdot \overline{9}$ & 2 & 13.3 \\
\hline 18 and older & 5 & $19 \cdot 2$ & 0 & 0.0 \\
\hline \multicolumn{5}{|l|}{ Ethnicity/race } \\
\hline Black or African American & 22 & 84.6 & 0 & 0.0 \\
\hline Hispanic or Latino & 3 & 11.5 & 2 & $13 \cdot 3$ \\
\hline White & 0 & 0.0 & 12 & 80.0 \\
\hline Other & 1 & 3.8 & 1 & $6 \cdot 7$ \\
\hline \multicolumn{5}{|l|}{ Job status } \\
\hline Yes & 3 & 11.5 & 1 & $6 \cdot 7$ \\
\hline No & 23 & 88.5 & 14 & 93.3 \\
\hline \multicolumn{5}{|c|}{ Federal breakfast/lunch participation } \\
\hline Yes & 13 & $50 \cdot 0$ & 0 & 0.0 \\
\hline No & 12 & $46 \cdot 2$ & 15 & $100 \cdot 0$ \\
\hline Missing & 1 & $3 \cdot 8$ & 0 & 0.0 \\
\hline
\end{tabular}

SES, socio-economic status. 
Table 2 Behavioural characteristics of the adolescent participants ( $n$ 41) according to SES, Austin, TX, USA, 2012

\begin{tabular}{|c|c|c|c|c|}
\hline \multirow[b]{2}{*}{ Characteristic } & \multicolumn{2}{|c|}{ Lower SES (n 26) } & \multicolumn{2}{|c|}{ Higher SES ( $n$ 15) } \\
\hline & $n$ & $\%$ & $n$ & $\%$ \\
\hline \multicolumn{5}{|c|}{ Frequency of fast-food purchases in past week } \\
\hline Never & 1 & $3 \cdot 8$ & 9 & $60 \cdot 0$ \\
\hline $1-2 \mathrm{~d} /$ week & 16 & 61.5 & 6 & $40 \cdot 0$ \\
\hline $3-4 \mathrm{~d} /$ week & 9 & 34.6 & 0 & 0.0 \\
\hline $5-7 \mathrm{~d} /$ week & 0 & 0.0 & 0 & 0.0 \\
\hline \multicolumn{5}{|c|}{ Weekly amount of dollars spent eating out } \\
\hline I do not eat out & 0 & 0.0 & 6 & $40 \cdot 0$ \\
\hline Less than \$US 5 & 3 & 11.5 & 2 & $13 \cdot 3$ \\
\hline \$US 5-\$0 & 11 & $42 \cdot 3$ & 4 & $26 \cdot 7$ \\
\hline More than SUS 10 & 12 & $46 \cdot 2$ & 3 & $20 \cdot 0$ \\
\hline \multicolumn{5}{|c|}{ Frequency of food label reading when eating out } \\
\hline Never & 10 & 38.5 & 10 & $66 \cdot 7$ \\
\hline Sometimes & 11 & $42 \cdot 3$ & 4 & $26 \cdot 7$ \\
\hline Most of the time & 3 & 11.5 & 1 & 6.7 \\
\hline Always & 0 & 0.0 & 0 & 0.0 \\
\hline Missing & 2 & $7 \cdot 7$ & 0 & 0.0 \\
\hline \multicolumn{5}{|c|}{ Purchase decisions based on calorie or nutrition labels } \\
\hline Never & 13 & $50 \cdot 0$ & 4 & $26 \cdot 7$ \\
\hline Sometimes & 7 & 26.9 & 8 & $53 \cdot 3$ \\
\hline Most of the time & 6 & $23 \cdot 1$ & 1 & $6 \cdot 7$ \\
\hline Always & 0 & 0.0 & 1 & $6 \cdot 7$ \\
\hline Missing & 0 & 0.0 & 1 & $6 \cdot 7$ \\
\hline \multicolumn{5}{|c|}{ Important considerations in food choices when eating out ${ }^{\star}$} \\
\hline Cost & \multicolumn{2}{|c|}{16} & \multicolumn{2}{|c|}{12} \\
\hline Taste & \multicolumn{2}{|c|}{15} & \multicolumn{2}{|c|}{12} \\
\hline Sodium & \multicolumn{2}{|c|}{3} & \multicolumn{2}{|c|}{3} \\
\hline Fat & \multicolumn{2}{|c|}{2} & \multicolumn{2}{|c|}{4} \\
\hline Calories & \multicolumn{2}{|c|}{1} & \multicolumn{2}{|c|}{3} \\
\hline Sugar & \multicolumn{2}{|c|}{1} & \multicolumn{2}{|c|}{3} \\
\hline None & \multicolumn{2}{|c|}{2} & \multicolumn{2}{|c|}{2} \\
\hline
\end{tabular}

SES, socio-economic status.

*Frequency of times the factor was mentioned.

higher-income communities reported that fat and sugar content, meal ingredients and food quality were more important factors when making meal choices (Table 3, row D).

Influence of parents. Adolescents from the high-income communities reported being influenced by parents when making food purchasing decisions and reported that their parents want them to eat healthy: '.. if you got something they don't approve of, you get the judging stare...'. Lowerincome community participants rarely reported their parents speaking with them about healthy eating and reported eating at fast-food restaurants with their parents often: 'My family, we don't worry about calories...'

Peer influences. Friends were also highly influential in meal choices for girls. In general, adolescents from the high-income communities tended to eat less healthy when eating with friends than when eating with their parents: 'Junk food is fun, it's one of the forbidden foods and not something you eat every day. It's fun to eat with other people... with friends...'. In addition, all girls reported sharing meals because it allowed them to spend less and get more variety in their choices (Table 3, row F). Highschool boys preferred to order on their own and did not report making meal choices based on friends' influence.

Location. Two environmental factors that influenced adolescents when making food purchasing decisions were physical location and cost. Girls from the high-income communities reported eating with their friends at restaurants located all over the city and reported wanting to try new places and order different items. The adolescents from the low-income communities reported being confined to walkable restaurants close to their homes or their school (Table 3, row G).

Cost. Cost was overwhelmingly the most important factor for meal decisions among adolescents from the lowincome communities. These adolescents reported selecting menu options to stretch the dollar and choosing familiar foods: 'When I buy something new and I don't like it, I think it's a waste of money... so I usually get the same thing.' Higher-income community participants also reported cost as influential when making meal choices with friends, but not when eating out with parents.

\section{Strategies for effective menu labels}

Participants were asked to provide suggestions on how to construct menu labels that were relevant to their age group. In order to facilitate this question, the researchers showed different examples of menu labels that are currently being used in the USA and in other countries on large poster boards. These examples were used as a starting point for the conversation. Participants were asked their reaction to the samples and then asked how/if these 
Table 3 Qualitative results from focus group discussions among of the adolescent participants by SES level, Austin, TX, USA, 2012

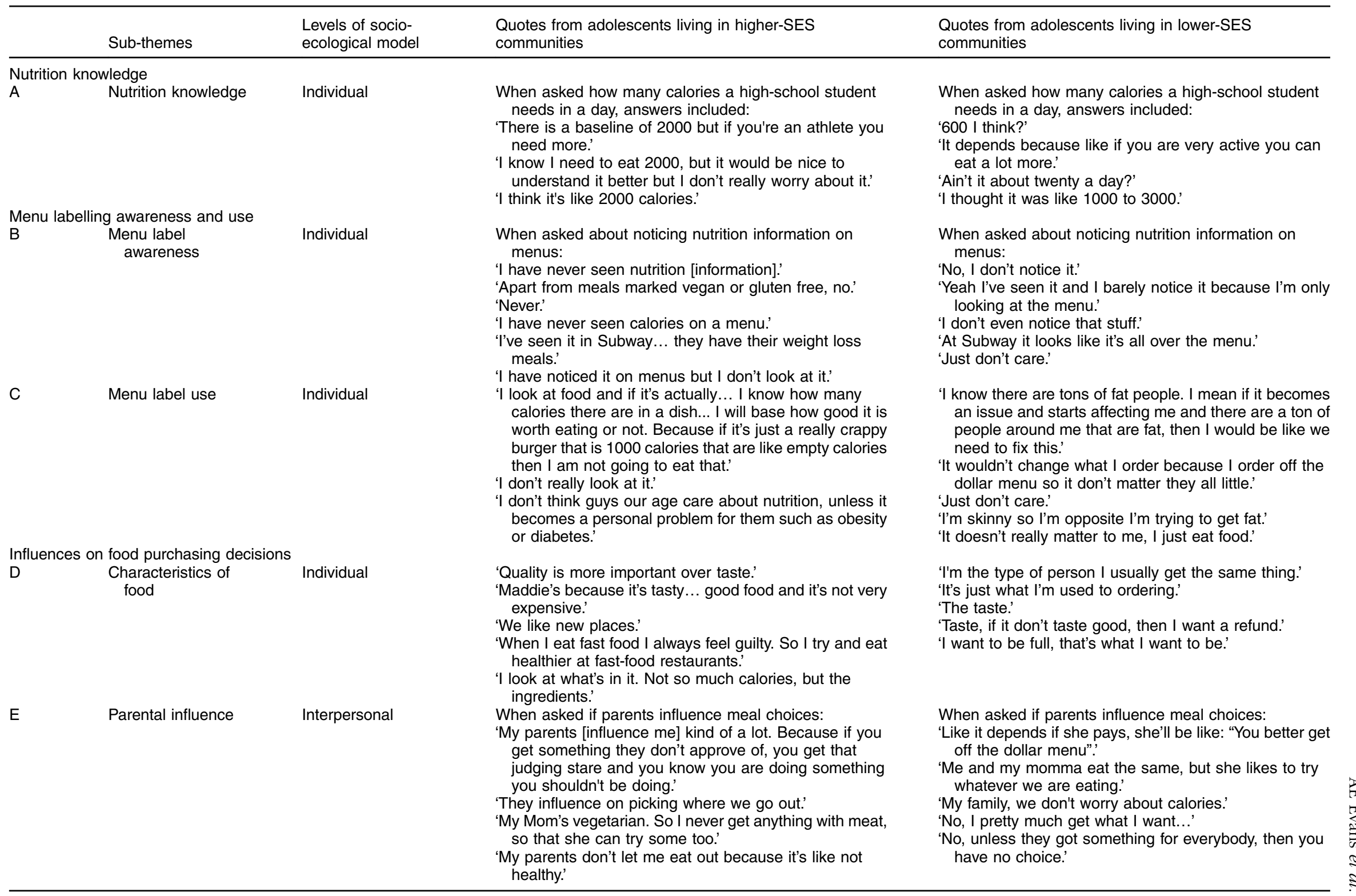


Table 3 Continued

\begin{tabular}{|c|c|c|c|}
\hline & Sub-themes & $\begin{array}{l}\text { Levels of socio- } \\
\text { ecological model }\end{array}$ & $\begin{array}{l}\text { Quotes from adolescents living in higher-SES } \\
\text { communities }\end{array}$ \\
\hline $\mathrm{F}$ & Friend influence & Interpersonal & $\begin{array}{l}\text { 'In general we eat more unhealthy with our friends... } \\
\text { whenever we go to our friend's house we can walk } t \\
\text { the corner store and gets tons of chips and cookies. } \\
\text { yeah and on sleepovers.' } \\
\text { 'Junk food is fun, it's one of the forbidden foods and nc } \\
\text { something you eat every day. It's fun to eat with othe } \\
\text { people... with friends...' } \\
\text { 'Well a lot of my [girl] friends we all like to eat everything } \\
\text { and so we're going to share because it's a lot cheape } \\
\text { 'It depends what my friends are getting because if they } \\
\text { are all getting salad then I am definitely not going to b } \\
\text { the one eating nachos [girl].' } \\
\text { 'My friends we like everything, so we are going to share } \\
\text { 'No, I just get what I was going to get.' } \\
\text { 'No.' }\end{array}$ \\
\hline
\end{tabular}

Quotes from adolescents living in lower-SES communities

'Well a lot of my friends we all like to eat everything, and so we're going to share because it's a lot cheaper.' 'No see how we do it is, I gets a fry, she gets a fry, she gets three cookies, and I gets two apple pie.

'A lot of different things so we can all try something

$$
\text { different.' }
$$

'We split everything so then everyone gets what they want, you know.'

'Me and my best friend would order the same thing. 'We want the same thing.'

'No.'

'If they say it's good I might wanna try it.'

'I'm the type of person I usually get the same thing. I already know how it tastes.

No I stick to what I know.'

'McDonalds, Jack in the Box because it is good food and it's cheap.'

'Same thing, McDonalds.'

'We walk down the trail and when you walk down, Jack and the Box is right there and then there is a store and then it's McDonalds.'

'We walk down the trail.'

'Yea and Taco Bell too.'

'The number one thing that influences my decision is cost.'

'It will vary where I go with parents or friends because don't have as much money to spend on myself with friends.'

'Large quantity of food and it's affordable.'

'Because it's not too expensive.'

'... It's a Chinese restaurant and it's cheap, and you can order a lot of food for not that much... it's not too unhealthy.'

When asked if knowledge about exercise required to burn off calories would make a difference in meal choice:

'Yeah, that would be terribly effective.'

'So I would keep eating, but I would feel horrible. It would ruin the eating experience.'

Oh yeah, you eat that meal but I have to do this much to burn that off, maybe I won't take it.'

When asked what adolescents would put on a menu label:

'It would be a goodness scale. Does it taste good, yeah, is it good for me, yeah or no. It would have yes or no questions because you don't want to have all the information you just want to look at it and see yes or no.'

'Something simple, is it healthy or not?
I had more money I would buy it, but if I don't have money l'm not.'

'When I buy something new and I don't like it I think it's a waste of money... so I usually get the same thing.'

When asked if knowledge about exercise required to burn off calories would make a difference in meal choice:

'I would die if I had to walk an hour.'

'Yeah, but it still wouldn't matter because I won't gain weight.'

When asked what adolescents would put on a menu label: 'Tell them what everything means, like calories, fat, sodium this is what it does to me

'Why should I have more or less of it, then I would probably be convinced, if they make it sound bad you aren't gonna want it.'

'How many chips were in a bag, and how many we can eat in a day. 
Table 3 Continued

\begin{tabular}{|c|c|c|c|c|}
\hline & Sub-themes & $\begin{array}{l}\text { Levels of socio- } \\
\text { ecological model }\end{array}$ & $\begin{array}{l}\text { Quotes from adolescents living in higher-SES } \\
\text { communities }\end{array}$ & $\begin{array}{l}\text { Quotes from adolescents living in lower-SES } \\
\text { communities }\end{array}$ \\
\hline & & & $\begin{array}{l}\text { 'I had the idea of possibly doing a much smaller print, } \\
\text { most people wouldn't notice, but the people that } \\
\text { actually did, would, having side-effects like on that on } \\
\text { medication. I think that would be great. Like possible } \\
\text { diarrhoea, constipation, or like even prolonged use risk } \\
\text { of death or heart attack. So when you are reading this } \\
\text { you are like I don't want to have diarrhoea or a heart } \\
\text { attack so I am just not going to eat this.' } \\
\text { 'The grading if it's good.' }\end{array}$ & $\begin{array}{l}\text { 'If y'all talked about the outcome situation, then yeah, they } \\
\text { won't do it.' }\end{array}$ \\
\hline J & Pictures & & $\begin{array}{l}\text { 'Show everything with a picture, you don't have to read } \\
\text { anything.' }\end{array}$ & $\begin{array}{l}\text { 'Pictures and photographs would be helpful.' } \\
\text { 'I would put fat kids on the one like that.' } \\
\text { 'How it looks is important.' }\end{array}$ \\
\hline K & Stop light system & & $\begin{array}{l}\text { '... So apparently they label all their food as green, } \\
\text { yellow, or red. Like a stoplights. Like red is like bad for } \\
\text { you, yellow you like can eat some of the time, and } \\
\text { green is eat this all of the time. So having something } \\
\text { like that on food labels would be helpful because it } \\
\text { would tell people how much to eat.' } \\
\text { 'Kind of what he said, like the green, yellow, or red. ... } \\
\text { design it so it is pretty easy to read even if it was pie } \\
\text { charts. Simple.' }\end{array}$ & \\
\hline $\mathrm{L}$ & Simple & & $\begin{array}{l}\text { 'Straightforward, familiar, colourful.' } \\
\text { 'Big writing.' } \\
\text { 'Nothing too small.' } \\
\text { 'Just something easy to read, something that you could } \\
\text { read in just a second. Like good, bad, or ok.' } \\
\text { 'I know how they have at Chili's they have peppers } \\
\text { marking the spiciness, so you could just have different } \\
\text { colour of circles...' } \\
\text { 'It's nice to look at it quickly, you don't have to stare at it.' }\end{array}$ & \\
\hline
\end{tabular}

SES, socio-economic status. 
menu labels could be improved. At the end of this specific discussion, participants were asked if there were other ways that this information could be portrayed effectively. The most popular suggestions included adding the number of miles or minutes necessary to burn off calories, or listing the health conditions resulting from eating specific foods: 'I would die if I had to walk an hour. I would eat salads and everything.' Other suggestions included using relevant pictures to present information or incorporating a traffic light system using big, bold letters or colours to present information: 'Show everything with a picture, you don't have to read anything.' Additionally, the higherincome girls reported being influenced by the ingredients listed next to meals and were interested in seeing labelling of fat, sugar and ingredients.

\section{Discussion}

The primary aim of the present study was to collect in-depth information from adolescents about their use of menu labels when eating out and, secondarily, to determine if there were differences according to socioeconomic status. In comparing the quantitative results obtained from a short survey, notable differences according to socio-economic status were observed. Participants living in lower-income areas reported eating out more often and spending more money eating out. This is somewhat counterintuitive, assuming that participants living in lower-income areas have less disposable income overall. However, previous studies support these findings ${ }^{(25,38,40)}$. It is important to note that the lower-income participants reported eating out at fast-food establishments while the higher-income participants reported eating out at more expensive sit-down eating establishments.

Overall, knowledge about appropriate daily energy intake range was fairly poor, especially among the participants living in lower-income areas. When asked about how many calories teens should eat every day, the lowerincome group's guesses ranged from 20 to 10000 calories per day. Higher-income participants, especially the girls, were more knowledgeable, perhaps because they also reported that their parents talk about this topic quite often. Other studies also suggest that higher-income adolescents tend to have a higher level of nutrition knowledge than lower-income adolescents ${ }^{(50,53)}$. This lack of knowledge is disturbing in that it points to one reason why menu labels providing only calorie information may not work among this age group.

Menu labelling awareness and use was extremely low among all participants. Most participants reported never having seen nutrition information on menu boards when eating out. At the time of the study there was no regulation in place requiring eating establishments to post nutrition information; however, certain fast-food chains were already displaying menu labels, so most of the participants probably were exposed to them. Nevertheless, it is possible that participants had not been to eating establishments with menu labels and, thus, these results are consistent with the adolescents' environment at the time of the study. However, when asked if they would use nutrition information if it was available when eating out, most adolescents (except girls from the higher-income communities) stated that they would not use it. Several boys mentioned they would use it to make sure they ordered the most calories possible. Previous studies with adolescents are congruent with our findings in that only $9 \%$ of 349 participants reported using menu labelling information if they noticed it ${ }^{(40)}$. Past studies have also shown that compared with males, females are more likely to use nutrition information ${ }^{(54,55)}$.

\section{Influences on food purchasing decisions}

In terms of what drives their food purchasing decisions, all adolescents reported that calorie content was not important. Fifty per cent of lower-income community participants and $27 \%$ of higher-income community participants reported that caloric information 'never' influences their choices when eating out. Instead, cost and taste were reported as the two most important factors (Table 2). These results are consistent with results from other studies ${ }^{(25,33,40)}$. In one study, when participants were asked to rate the importance of price, taste, nutrition and convenience when purchasing food, taste was the most highly rated factor and nutrition was the least likely factor to be rated as very or somewhat important ${ }^{(25)}$. Among participants from the lower-income communities, familiarity and ability to walk to eating establishments determined eating establishment selection. Elbel $e t a l$. also found that easy access and convenience of location were important considerations for teens in choosing where to eat ${ }^{(40)}$.

Both parents and peers are important influences when eating out, underscoring the importance of the social environment. However, an important difference was that participants from the higher-income communities are more often exposed to social norms that promote healthier eating, while adolescents from the lower-income communities are more often exposed to social norms that promote less healthy eating ${ }^{(38)}$. In the present study, higher-income community participants reported that both parents and peers eat out at restaurants with wait staff or more 'upscale' restaurants, while parents and peers of lower-income community teens tend to eat at fast-food establishments.

\section{Strategies for effective menu label formats}

Overall, participants reported that menu labels in their current format are not useful or relevant to them. However, if labels can be constructed in such a way to make them personally relevant, then they were willing to consider using the labels. Participants suggested the following methods for making labels more personally 
relevant: (i) post the number of minutes/miles needed to 'run off' the calories consumed; (ii) add a silhouette figure that is thin, average or overweight next to each food item to indicate the relative number of calories in the food; and (iii) use simple designs with bold colours such as the traffic light design. If calories had to be posted on the menu, then the participants wanted to have the average daily required calories listed as well.

Experimental studies to test the actual effectiveness of specific menu labelling designs have been mixed. There is some evidence that providing physical activity equivalents as opposed to providing caloric information may be an effective format for adolescents. Bleich et al. conducted a study with low-income adolescents and found that by providing calorie information as a physical activity equivalent, the odds ratio of reducing sugar-sweetened beverage purchases was reduced to 0.51 (95\% CI 0.31 , $0 \cdot 85)^{(41)}$. Another study which assessed several formats of menu labelling found that when considering the entire sample of adolescents and adults, $71 \%$ of participants preferred calorie information over physical activity information. However, when broken down by age group (younger than 35 years $v$. older than 35 years), the younger group was much more likely to prefer the physical activity information (43\% v. $22 \%$, respectively; $P<0.006)^{(56)}$.

Providing caloric menu information through simple graphics is another promising strategy. Children significantly improved their meal choices when exposed to menus with heart symbols $v$. children exposed to menus with calorie and fat content or children exposed to menus with no nutrition information ${ }^{(9)}$. Adults exposed to colour-coded menus (red/green circles indicating higher/ lower calorie choices) ordered menu items with fewer calories $^{(57)}$. Additionally, researchers in Spain found that adolescents ordered menu items with significantly less calories, total fat, saturated fat, sugar and salt when ordering from a menu with traffic light colour-coded nutrition information compared with when ordering from a menu with the same nutrition information, but without colour coding ${ }^{(58)}$. Further, nearly $90 \%$ of the adolescents preferred the traffic light colour-coded menu to the nocolour menu because it was easier to understand ${ }^{(58)}$. However, in another study, menu labels with symbols did not result in changes in calories or fat of the menu items ordered $^{(59)}$. No studies using symbols of different sized silhouettes on menus have been conducted with adolescents.

\section{Limitations}

As with any study, the present one has limitations. First, as with many qualitative studies, the sample was a convenience sample and the sample size was small, limiting the generalizability of the findings. However, after five focus groups, the information received from participants became redundant, an indication that the saturation level was reached. A second limitation is that the lower-income community participants were mostly of ethnic minority background, while the higher-income community participants were mostly white. This breakdown of ethnic background is not surprising given data showing that families of ethnic minority backgrounds tend to live in lower-income neighbourhoods. However, because results are confounded by ethnic makeup, it is more difficult to attribute results solely to living in low-income or highincome communities, and cultural factors surely play an important role as well.

\section{Implications and conclusion}

Menu labelling has been identified as a potential strategy to help individuals make healthier choices when eating out. However, to have this impact among all sub-populations, including adolescents who tend to use a high percentage of their disposable income on eating out, more research is needed. While the current format of providing the number of calories next to a menu item may be effective for adults, results of the current, small qualitative study suggest that this format of menu labelling may not be the most effective way to provide this information to adolescents. Many of the adolescents in the study were not knowledgeable about the correct range of recommended caloric intake, thus seeing a number of calories next to a food item did not have any meaning for them. Different formats suggested by focus group participants included presenting calorie information in the form of exercise equivalents, using a simple traffic light system, providing pictures of thin, average and overweight people next to specific food items, or listing calories along with suggested daily caloric intake. Given that there is a paucity of studies examining the impact of different menu label designs on adolescents, it is difficult to conclude what will best work with this age group. Future longitudinal quantitative studies to determine the impact of different designs on adolescents' purchasing decisions are warranted.

Because of the recently enacted national menu labelling legislation, it is not realistic to suggest changing the format of menu labelling in the USA. The results of the present study underscore the need to conduct more research to gain a better understanding of how the current format can be enhanced to be more effective with adolescents. Results indicate a need to provide more nutrition education to adolescents as well. In addition, although it will be difficult to make any changes to the menu labelling format in the USA, results from the current study can benefit other countries that may be in the process of creating similar legislation.

\section{Acknowledgements}

Acknowledgements: The authors would like to thank the participants and the adults at the locations of recruitment who made the study possible. They also would like to 
thank Shadia Lahlou and Cori Nemec Fair for providing technical assistance for this manuscript. Financial support: This work was supported by the Michael \& Susan Dell Center for Healthy Living at the University of Texas School of Public Health. The Michael \& Susan Dell Center for Healthy Living had no role in the design, analysis or writing of this article. Conflict of interest: None. Authorship: A.E.E. designed the study, created the methodology, analysed the data and developed the manuscript. S.R.W. helped design the study, recruited participants, conducted focus groups and helped analyse the data; she also assisted in writing of the manuscript. K.J.M. recruited participants and conducted focus groups; she also assisted in writing of the manuscript. S.C. conducted focus groups and led the data analysis; he also assisted in writing of the manuscript. E.A.V. helped analyse the data and reviewed the manuscript. R.B.N. helped design the study and critically reviewed the manuscript. Ethics of human subject participation: This study was conducted according to the guidelines laid down in the Declaration of Helsinki and all procedures involving human subjects were approved by the Institutional Review Board of the University of Texas Health Science Center. Written informed consent was obtained from all subjects.

\section{References}

1. Stewart H, Blisard N \& Jolliffe D (2006) Let's Eat Out: Americans Weigh Taste, Convenience, and Nutrition. Economic Information Bulletin no. EIB-19. Washington, DC: US Department of Agriculture, Economic Research Service; available at http://www.ers.usda.gov/publications/eibeconomic-information-bulletin/eib19.aspx\#.U_U51BaHuzC

2. Guthrie JF, Lin BH \& Frazao E (2002) Role of food prepared away from home in the American diet, 1977-78 versus 1994-96: changes and consequences. J Nutr Educ Behav 34, 140-150.

3. Binkley JK, Eales J \& Jekanowski M (2000) The relation between dietary change and rising US obesity. Int J Obes Relat Metab Disord 24, 1032-1039.

4. Bowman SA, Gortmaker SL, Ebbeling CB et al. (2004) Effects of fast-food consumption on energy intake and diet quality among children in a national household survey. Pediatrics 113, 112-118.

5. French S, Neumark-Sztainer D, Fulkerson JA et al. (2001) Fast food restaurant use among adolescents: associations with nutrient intake, food choices, behavioral and psychosocial variables. Int J Obes Relat Metab Disord 25, 1823-1833.

6. Wiecha J, Finkelstein D \& Troped P (2006) School vending machine use and fast-food restaurant use are associated with sweetened beverage intake in youth. J Am Diet Assoc 106, 1624-1630.

7. Schmidt M, Affenito S \& Striegel-Moore RH (2005) Fast-food intake and diet quality in black and white girls. Arch Pediatr Adolesc Med 159, 626-631.

8. Larson N, Neumark-Sztainer D, Laska MN et al. (2011) Young adults and eating away from home: associations with dietary intake patterns and weight status differ by choice of restaurant. J Am Diet Assoc 111, 1696-1703.

9. Stutts MA, Zank GM, Smith KH et al. (2011) Nutrition information and children's fast food menu choices. J Consum Aff 45, 52-86.
10. Jeffery RW, Baxter J, McGuire M et al. (2006) Are fast food restaurants an environmental risk factor for obesity? Int $J$ Behav Nutr Phys Act 3, 2.

11. Wansink B \& Chandon P (2006) Can 'low-fat' nutrition labels lead to obesity? J Mark Res 43, 605-617.

12. Chandon P \& Wansink B (2007) Is obesity caused by calorie underestimation? A psychophysical model of meal size estimation. J Mark Res 44, 84-99.

13. Chandon P \& Wansink B (2007) The biasing health halos of fast-food restaurant health claims: lower calorie estimates and higher side-dish consumption intentions. J Consum Res 34, 301-314.

14. Burton S, Creyer EH, Kees J et al. (2006) Attacking the obesity epidemic: the potential health benefits of providing nutrition information in restaurants. Am J Public Health 96, $1669-1675$.

15. Block JP, Condon SK, Kleinman K et al. (2013) Consumers' estimation of calorie content at fast food restaurants: cross sectional observational study. BMJ 346, f2907.

16. Elbel B (2011) Consumer estimation of recommended and actual calories at fast food restaurants. Obesity (Silver Spring) 19, 1971-1978.

17. Swartz JJ, Braxton D \& Viera AJ (2011) Calorie menu labeling on quick-service restaurant menus: an updated systematic review of the literature. Int J Behav Nutr Phys $\mathbf{8}, 135$.

18. Tandon PS, Wright J, Zhou C et al. (2010) Nutrition menu labeling may lead to lower-calorie restaurant meal choices for children. Pediatrics 125, 244-248.

19. Chu YH, Frongillo EA, Jones SJ et al. (2009) Improving patrons' meal selections through the use of point-of-selection nutrition labels. Am J Public Health 99, 2001-2005.

20. Bollinger B, Leslie P \& Sorensen A (2010) Calorie Posting in Chain Restaurants. NBER Working Paper no. 15648. Cambridge, MA: National Bureau of Economic Research; available at http://www.nber.org/papers/w15648.pdf?new_ window $=1$

21. Roberto CA, Larsen PD, Agnew H et al. (2010) Evaluating the impact of menu labeling on food choices and intake. Am J Public Health 100, 312-318.

22. Finkelstein EA, Strombotne KL, Chan NL et al. (2011) Mandatory menu labeling in one fast-food chain in King County, Washington. Am J Prev Med 40, 122-127.

23. Dumanovsky T, Huang CY, Nonas CA et al. (2010) Consumer awareness of fast food calorie information in new York City after implementation of a menu labeling regulation. Am J Public Health 100, 2520-2525.

24. Tandon PS, Zhou C, Chan NL et al. (2011) The impact of menu labeling on fast-food purchases for children and parents. Am J Prev Med 41, 434-438.

25. Harnack LJ, French SA, Oakes JM et al. (2008) Effects of calorie labeling and value size pricing on fast food meal choices: results from an experimental trial. Int J Behav Nutr Phys 5, 63.

26. Vadiveloo MK, Dixon LB \& Elbel B (2011) Consumer purchasing patterns in response to calorie labeling legislation in New York City. Int J Behav Nutr Phys 8, 51.

27. Elbel B, Kersh R, Brescoll VL et al. (2009) Calorie labeling and food choices: a first look at the effects on low-income people in New York City. Health Aff (Millwood) 28, w1110-w1121.

28. Dumanovsky T, Huang CY, Nonas CA et al. (2011) Changes in energy content of lunchtime purchases from fast food restaurants after introduction of calorie labeling: cross sectional customer surveys. BMJ 343, d4464.

29. Downs JS, Loewenstein G \& Wisdom J (2009) Strategies for promoting healthier food choices. Am Econ Rev 99, 159-164.

30. Wethington H, Maynard LM \& Blanck HM (2013) Use of calorie information at fast food and chain restaurants among US youth aged 9-18 years, 2010. J Public Health (Oxf) 35, 354-360. 
31. Krieger JW, Chan NL, Saelens BE et al. (2013) Menu labeling regulations and calories purchased at chain restaurants. Am J Prev Med 44, 595-604.

32. Auchincloss AH, Young C, Davis AL et al. (2013) Barriers and facilitators of consumer use of nutrition labels at sitdown restaurant chains. Public Health Nutr 16, 2138-2145.

33. Schindler J, Kiszko K, Abrams C et al. (2013) Environmental and individual factors affecting menu labeling utilization: a qualitative research study. J Acad Nutr Diet 113, 667-672.

34. Kiszko KM, Martinez OD, Abrams C et al. (2014) The influence of calorie labeling on food orders and consumption: a review of the literature. J Community Health 39, $1248-1269$

35. Nestle M (2010) Health care reform in action: calorie labeling goes national. $N$ Engl J Med 362, 2343-2345.

36. McNeal JU (1998) Tapping the three kids' markets. Am Demogr 20, 36-41.

37. McGinnis JM, Gootman JA \& Kraak VI (2006) Food Marketing to Children and Youth: Threat or Opportunity? Washington, DC: National Academies Press.

38. French SA, Story M, Neumark-Sztainer D et al. (2001) Fast food restaurant use among adolescents: associations with nutrient intake, food choices and behavioral and psychosocial variables. Int J Obes Relat Metab Disord 25 1823-1833.

39. Lin BH, Guthrie J \& Frazao E (1999) Quality of children's diets at and away from home: 1994-96. Food Rev 22, 2-10.

40. Elbel B, Gyamfi J \& Kersh R (2011) Child and adolescent fast-food choice and the influence of calorie labeling: a natural experiment. Int J Obes (Lond) 35, 493-500.

41. Bleich SN, Herring BJ, Flagg DD et al. (2012) Reduction in purchases of sugar-sweetened beverages among lowincome black adolescents after exposure to caloric information. Am J Public Health 102, 329-335.

42. Yamamoto JA, Yamamoto JB, Yamamoto BE et al. (2005) Adolescent fast food and restaurant ordering behavior with and without calorie and fat content menu information. J Adolesc Health 37, 397-402.

43. Block JP, Scribner RA \& DeSalvo KB (2004) Fast food, race/ ethnicity, and income. Am J Prev Med 27, 211-217.

44. Morland K, Wing S, Roux AD et al. (2002) Neighborhood characteristics associated with the location of food stores and food service places. Am J Prev Med 22, 23-29.
45. Morland KB \& Evenson KR (2009) Obesity prevalence and the local food environment. Health Place 15, 491-495.

46. Simon PA, Kwan D, Angelescu A et al. (2008) Proximity of fast food restaurants to schools: do neighborhood income and type of school matter? Prev Med 47, 284-288.

47. Peterson-Sweeney K (2005) The use of focus groups in pediatric and adolescent research. J Pediatr Health Care 19 , 104-110.

48. McLeroy KR, Bibeau D, Steckler A et al. (1988) An ecological perspective on health promotion programs. Health Educ Q 15, 351-377.

49. Krueger RA (1998) Analyzing and Reporting Focus Group Results. Thousand Oaks, CA: Sage Publications.

50. Evans AE, Wilson DK, Buck J et al. (2006) Outcome expectations, barriers, and strategies for healthful eating: a perspective from adolescents from low-income families. Fam Community Health 29, 17-27.

51. Evans A, Chow S, Jennings R et al. (2011) Traditional foods and practices of Spanish-speaking Latina mothers influence the home food environment: implications for future interventions. J Am Diet Assoc 111, 1031-1038.

52. LeCompte MD \& Schensul JJ (1999) Analyzing and Interpreting Ethnographic Data. Walnut Creek, CA: AltaMira Press.

53. Story M \& Resnick MD (1986) Adolescents' views on food and nutrition. J Nutr Educ 18, 188-192.

54. McCullum C \& Achterberg CL (1997) Food shopping and label use behavior among high school-aged adolescents. Adolescence 32, 181-197.

55. Bender MM \& Derby BM (1992) Prevalence of reading nutrition and ingredient information on food labels among adult Americans: 1982-1988. J Nutr Educ 24, 292-297.

56. Fitch RC, Harnack LJ, Neumark-Sztainer DR et al. (2009) Providing calorie information on fast-food restaurant menu boards: consumer views. Am J Health Promot 24, 129-132.

57. Liu PJ, Roberto CA, Liu LJ et al. (2012) A test of different menu labeling presentations. Appetite 59, 770-777.

58. Babio N, Vicent P, López L et al. (2014) Adolescents' ability to select healthy food using two different front-of-pack food labels: a cross-over study. Public Health Nutr 17, 1403-1409.

59. Holmes A, Serrano E, Machin J et al. (2013) Effect of different children's menu labeling designs on family purchases. Appetite 62, 198-202. 